\title{
Safe use of chemicals by professional users and health care specialists
}

\author{
MARGARITA APATSIDOU $^{1 *}$, IOANNA KONSTANTOPOULOU $^{1 *}$, ELENI FOUFA $^{2}$, \\ KONSTANTINOS TSAROUHAS ${ }^{3}$, PETROS PAPALEXIS ${ }^{2}$, RAMIN REZAEE ${ }^{4}$, \\ DEMETRIOS A. SPANDIDOS ${ }^{5}$, DEMETRIOS KOURETAS ${ }^{1}$ and CHRISTINA TSITSIMPIKOU ${ }^{2}$
}

\begin{abstract}
${ }^{1}$ Department of Biochemistry-Biotechnology, School of Health Sciences, University of Thessaly, Viopolis, 41500 Larissa; ${ }^{2}$ General Chemical State Laboratory of Greece, Ampelokipi, 11521 Athens; ${ }^{3}$ Department of Cardiology, University Hospital of Larissa, Mezourlo, 41110 Larissa, Greece; ${ }^{4}$ Clinical Research Unit, Faculty of Medicine, Mashhad University of Medical Sciences, Mashhad 91778-99191, Iran; ${ }^{5}$ Department of Virology, Medical School, University of Crete, Heraklion, 71003 Crete, Greece
\end{abstract}

Received November 10, 2017; Accepted December 13, 2017

DOI: $10.3892 /$ br.2018.1037

\begin{abstract}
The awareness of Greek professional users and health care specialists regarding the safe use of chemicals was investigated, to be the best of our knowledge, for the first time after the introduction of Regulations (EC) 1907/2006 (REACH) and 1272/2008 (CLP) on chemicals. A total of 200 professional users and 150 health care specialists from various regions of Greece contributed to the use of a closed-ended, anonymous and validated questionnaire. The findings showed that over $85 \%$ of the responders were not aware of classification, labelling and packaging (CLP) and $67.8 \%$ of the responders were unaware of any changes made in the labeling of the products they were using. The majority $(>75 \%)$ of individuals were cognizant that they were using hazardous products; however, the perception of hazard varied significantly between the two groups $(\mathrm{P}=0.012)$ and statistically were dependent on the educational $(\mathrm{P}=0.022)$ and the profession $(\mathrm{P}=0.014)$ level. One third of the professional users read the label as the main source of information for the product, while for health care specialists the number increased to $65 \%$ and a strong correlation was detected with the educational level $(\mathrm{P}=0.017)$. In both groups, $7 \%$ of professional users and health care specialists declared that hazard communication through product labeling is not well understood. The use of personal protective equipment (PPE) is almost universal for health care specialists with women being more sensitive
\end{abstract}

Correspondence to: Dr Christina Tsitsimpikou, General Chemical State Laboratory of Greece, 16 Anastasiou Tsocha Street, Ampelokipi, 11521 Athens, Greece

E-mail: chtsitsi@yahoo.com

"Contributed equally

Key words: CLP, labeling, chemicals, safe use, poisoning centres
$(\mathrm{P}=0.041)$, while $25 \%$ of the professional users do not use any PPE. Almost $60 \%$ of the health care specialists are required to provide instructions regarding the safe use of chemicals or the action to be undertaken in case of accident. In the latter situation, the National Poisoning Centre is the reference point for information. Limited use of the safety data sheets has been observed both for professional users (18\%) and health care specialists $(23 \%)$. In conclusion, rising awareness campaigns are needed, in collaboration with trade unions and health care professional associations, in order to alert professionals regarding the safe use of chemicals and protect human health and the environment.

\section{Introduction}

Chemicals constitute a part of everyday life. Approximately 1,000 new chemicals are placed on the market each year, usually found as mixtures in commercial products, while more than 100,000 chemical substances are used worldwide (1). Many of these chemicals may, especially if not properly used, possess hazards for human health and be toxic to the environment.

The hazards of chemicals can be classified based on physical, chemical and ecotoxicological endpoints using criteria developed in the framework of scientific or regulatory processes (2). A number of national and international schemes have been developed over the past 50 years. To avoid multiplicity and confusion at the user level, the globally harmonized system (GHS) for the classification and labeling of chemicals was adopted in 1992 during the Rio Earth summit. GHS includes easily understandable symbols that can be applied in the manufacture, transport, use and disposal of chemical substances (2).

At a European Union (EU) level, two Regulations have been introduced, Regulation (EC) 1907/2006 (REACH) and Regulation (EC) 1272/2008 aimed to effectively handle hazards and risks from chemicals. The new EU chemicals legislation applies to all industry sectors dealing with chemicals along the 
entire supply chain. It therefore makes companies responsible for the safety of chemicals they place on the market.

The CLP Regulation, which is based on GHS, ensures that the hazards presented by chemicals are clearly communicated to workers and consumers in the European Union through the classification and labelling of chemicals. The industry must establish the potential risks to human health and the environment of substances and mixtures prior to placing them on the market as commercial products, by classifying them using the classification, labelling and packaging (CLP) criteria, in line with the identified hazards. The need to develop harmonized criteria for classification is essential in ensuring effective communication of the risk (3). Hazardous chemicals also have to be accordingly labeled using hazard and precautionary statements and pictograms.

In addition, suppliers established in the EU and placing hazardous products on the market have to provide standardised information to be used only by Poison Centres (Article 45 of the CLP). The Poison Centres provide medical advice in case of poisoning due to exposure to hazardous chemicals or to other toxic agents to the general public and to physicians. Poison centres in the EU answer on average 600,000 calls for support each year. However, EU legislation does not specify the precise information needed for this product notification. Therefore, varying requirements have been developed by each EU member state (4).

Safety data sheets (SDSs) are the main communication tool under the REACH Regulation between suppliers and users of substances and mixtures and it is a regulatory obligation for the industry. SDSs include information on the physical, chemical and hazardous properties of the substance or mixture as well as instructions for their handling, disposal and transport, and for first-aid, fire-fighting and exposure control measures.

The aim of the present study was to assess for the first time, to the best of our knowledge, the level of comprehension of the hazard and risk communication and awareness regarding the safe use of chemicals among Greek professional users and health care specialists eight years after the introduction of the respective EU legislation.

\section{Materials and methods}

A total of 1,500 individuals (850 industrial workers and professional users of chemicals from 35 different small and medium enterprises, self-employed professionals included, and 650 health care specialists from 6 public and private hospitals/medical centres, 40 private practitioners included), in Athens; Thessaloniki; Larissa; Ionnina; Patras and Heraklion Crete, Greece, were asked to answer an anonymous validated, self-administered questionnaire with 26 close-ended questions from May 2016 to April 2017. The questionnaire was left at the reception desk of the various workplaces, accompanied with an explanatory opening page, where it was stated that the results of the survey were to be published. The return of the completed questionnaire was considered as written consent of the study population. A total of 350 individuals (200 workers and professional users, 150 health care specialists) returned the questionnaire by placing it in a specifically marked receptacle at the reception desk of the various workplaces (return rate $23.3 \%$, in the range of the typical self-completed surveys) (5).
The questionnaire was developed at the University of Thessaly, Department of Biochemistry and Biotechnology (Larissa, Greece) in the framework of the MSc Course on Toxicology and was structured in three sections. The first section addressed demographic information (6 questions); the second investigated the risk/hazard communication of chemicals (14 questions); and the third explored the use and application of personal protective measures (6 questions).

Once the questionnaire was constructed, a multidisciplinary group of professionals that were not participating in the research group was asked to review the document and provide input. This expert group consisted of a toxicologist, a regulatory officer, an officer from the industry and a psychiatrist. The group provided input on the general content and face validity of the questionnaire (Content Validity Ratio-CRV $=0.993$, $\mathrm{P}<0.05)(6)$, which was proven complete and adequate for distribution.

The 103rd General Assembly of Specific Interest (09/03/2016) of the Department of Biochemistry and Biotechnology, University of Thessaly, provided approval for the conduct of the study and distribution of the questionnaire, as part of the dissertation theses of the students M.A. and I.K.

Statistical analysis. Statistical analysis was performed using the SPSS 22.0 software (IBM Corp., Armonk, NY, USA). Descriptive data were calculated as frequencies and percentages. Chi-square $\left(\chi^{2}\right)$ tests were computed to reveal meaningful associations between supplements use and the categorical study variables (sex and level of education) and Pearson's correlation was performed for continuous variables (i.e., age and exercise years). $\mathrm{P}<0.05$ was considered to indicate a statistically significant difference.

\section{Results}

Demographic characteristics. The demographic characteristics of the study population are shown in Table I. Professional users (group 1) and health care specialists (group 2) were of statistically similar age $(\mathrm{P}=0.323)$ and work experience $(\mathrm{P}=0.224)$. Women are statistically more in the health care specialists group, while men dominate the professional workers group. Twenty different professions were identified in the participants of group 1, including industrial workers (chemical products, plastics, pharmaceuticals, food industry and energy products/fuels), gas station employees, painters, carpenters, farmers, hairdressers and drivers. The vast majority of these professions belong to the private sector $(>80 \%)$. The level of education in group 1 was significantly lower than 2, as expected. More specifically, in group 1,81\% of the responders did not go to University or attend post-graduate courses, whereas in group 2 the respective value was $29 \%$. Of note is the low percentage of professional users of chemicals with no diagnosed health problems $(28 \%)$, while the prevalence of allergies (skin and respiratory system) is high in this population $(>50 \%)$. The picture is opposite in health care specialists.

Perception of various GHS pictograms. In several issues the two groups had statistically similar responses. Over $85 \%$ of the responders are not aware of the CLP Regulation per se, while $20 \%$ of professional users of chemicals are aware of the 
Table I. Demographical characteristics and diagnosed health status, type of working activity, work experience and educational level of the studied population.

\begin{tabular}{|c|c|c|}
\hline Characteristics & $\begin{array}{c}\text { Professional } \\
\text { users }\end{array}$ & $\begin{array}{l}\text { Health care } \\
\text { specialists }\end{array}$ \\
\hline Population (no) & 200 & 150 \\
\hline Age (years) & $41.8 \pm 7.5(21-61)$ & $38.8 \pm 9.5(24-64)$ \\
\hline \multicolumn{3}{|l|}{ Sex } \\
\hline Male & $115(60)$ & $55(37)$ \\
\hline Female & $85(40)$ & $95(63)$ \\
\hline \multicolumn{3}{|l|}{ Occupation } \\
\hline Workers (private sector) & 78 (39) & \\
\hline Workers (public sector) & 37 (18) & \\
\hline Self-employed & $85(42)$ & \\
\hline Medical doctors & & $116(77)^{\mathrm{a}}$ \\
\hline Nurses & & $22(15)$ \\
\hline Clinical chemists & & $12(8)$ \\
\hline Working experience (years) & $12.0 \pm 8.80(1-40)$ & $16.2 \pm 9.78(5-52)$ \\
\hline \multicolumn{3}{|l|}{ Education } \\
\hline Primary & $42(21)$ & $0(0)$ \\
\hline Secondary & $74(37)$ & $11(7)$ \\
\hline Technological & $46(23)$ & $33(22)$ \\
\hline University & $22(11)$ & $63(42)$ \\
\hline Post-graduate & $18(9)$ & $51(32)$ \\
\hline \multicolumn{3}{|l|}{ Diagnosed health problems } \\
\hline None & $56(28)$ & $104(69)$ \\
\hline Dermatological problems & $66(33)$ & $4(3)$ \\
\hline Respiratory problems & 38 (19) & $4(3)$ \\
\hline Musculoskeletal problems & $20(10)$ & $9(6)$ \\
\hline Cardiovascular problems & $4(2)$ & $2(1)$ \\
\hline Hypertension & $10(5)$ & $9(6)$ \\
\hline Other & $6(3)$ & $18(12)$ \\
\hline
\end{tabular}

${ }^{\mathrm{a}}$ Numbers in parentheses are percentages.

REACH Regulation. Over $65 \%$ of the responders did not notice any changes in the labeling of the products being used. The most common pictogram encountered is the old hazard symbol of a black cross on an orange background from the Dangerous Substances/Products Directives (approximately 40\%), which became obsolete in June 2015. In general, 50-60\% of professional users perceive pictograms adequately, while for health care specialists the percentage rises to $80 \%$. Nevertheless, both groups understand only the corrosive hazard for the skin/eyes in pictogram GHS05 and only $8 \%$ in group 1 and $26 \%$ in group 2 also comprehended the corrosivity for metals depicted by the same pictogram (Fig. 1). Over 65\% of the responders consider pictograms GHS06 and GHS08 equally hazardous for human health, but only $5 \%$ in group 1 expect carcinogenicity or reproductive toxicity to be communicated with the use of GHS08 (Fig. 2).

The majority of the responders $(>75 \%)$ are aware of the use of hazardous products during their everyday life, but the perception of hazard and the severity varies significantly between the two groups $(\mathrm{P}=0.012)$ and statistically depends on the educational $(\mathrm{P}=0.022)$ and professional $(\mathrm{P}=0.014)$ level. Professional users declare that they commonly use flammable liquids (26\%), while 7\% declare use of carcinogens and chemicals hazardous for the environment.

In general, age $(\mathrm{P}=0.02)$, work experience $(\mathrm{P}=0.025)$ and profession $(\mathrm{P}=0.022)$ significantly correlate with the level of familiarization with CLP. One third of the professional users enrolled in this study read the label as the main source of information for the product, while for health care specialists the number increased to $65 \%$. A strong correlation was detected with the educational level of the responders $(\mathrm{P}=0.017)$. In both groups a significant $7 \%$ declared that hazard communication through the labeling of the product is not well understood. Limited use of SDSs regarding the safe use of chemicals has been observed both in professional users $(18 \%)$ and in health care specialists $(23 \%)$. 


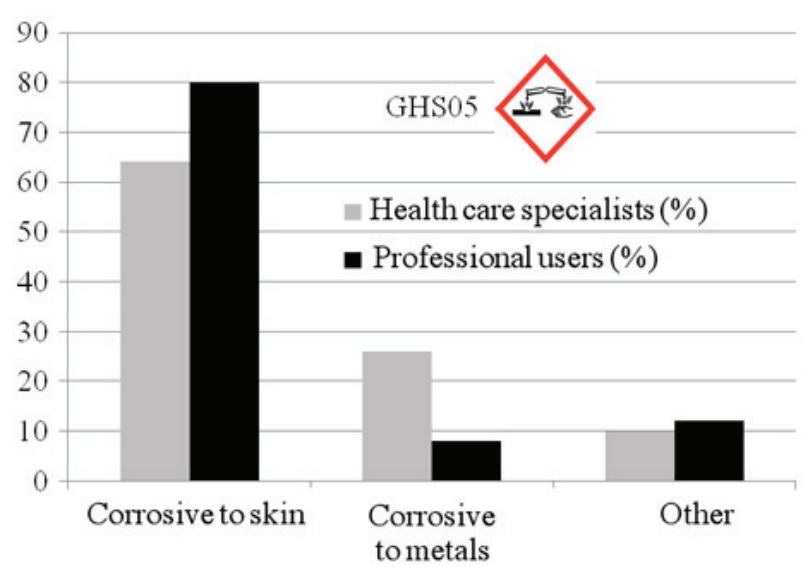

Figure 1. Perception of the pictogram GHS05 by the study population.

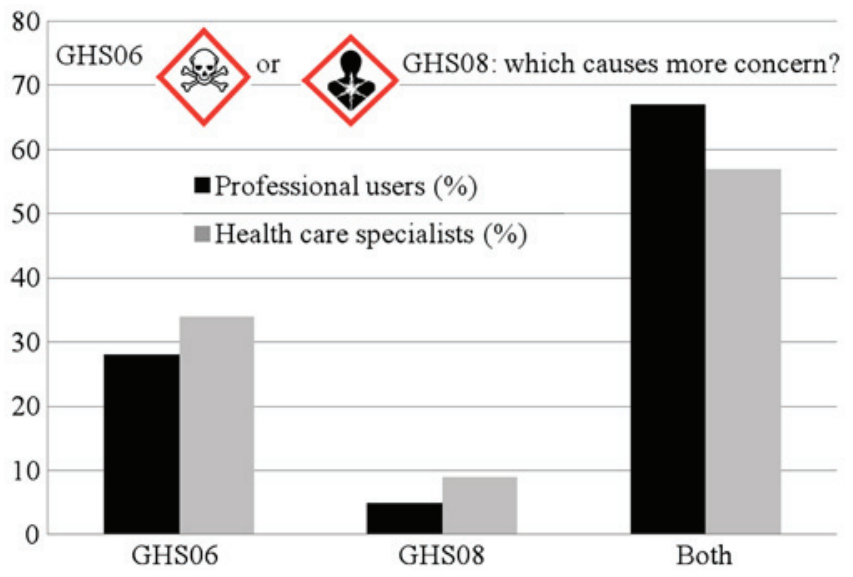

Figure 2. Perception of the hazard severity depicted by pictograms GHS06 and GHSO8 by the study population.

an increased risk of term (15). An association has also been reported between textile industry and different types of cancer including lung, bladder, colorectal and breast cancer (16).

In the present study, $72 \%$ of professional users of chemicals face health issues connected to skin and respiratory sensitisation.

Several studies have attempted to elucidate the comprehension of the legislation on chemicals and the hazard communication among workers and the general public (17-21).

Pictograms are the prevailing element in hazard/risk communication. It has been shown that the underlying core elements that enhance understanding of GHS pictograms, which are also essential in developing competent individuals in the use of SDSs, are training and education (22). Cleaning workers found not to be familiar with the pictograms had not been properly informed on the safe usage of chemicals by their employers (20). Age and educational level may impact workers' performance and cognitive process of comprehension of pictograms (19), as evidenced in the present study. Some pictograms are more easily perceived, while others remain controversial, such as GHS05, GHS06 and GHS08, as identified in our study. Similar concerns have been raised regarding the labeling of fragrances (23).

In a meta-analysis of 9 research studies published from 1983 to 2005 evaluating the relationship between literacy and hazard communication three main gaps were recognized regarding lack of learner involvement to improve hazard communication, lack of employer assessment of employee understanding of training provided, and lack of studies assessing retention of the material taught and its application at the worksite (18). In the present study, $30 \%$ of the professional users of chemicals tend to perceive the hazard/risk of a chemical after instruction by the employer or the shift supervisor to use PPE. Of note, low PPE compliance persists despite worker awareness of herbicide exposure risks, potentially as a result of the influence of the sex dynamics and social culture (24).

Appropriate work practices and selection and use of PPE are strongly recommended and measurements at the workplace have proven the efficacy thereof $(25,26)$. Nevertheless, use of PPEs is restricted, as observed in the present study. Farmers that are overexposed to pesticides toxicity do not use PPE (27).

On the other hand, disposable latex gloves commonly worn during pregnancy in occupations classified as possibly or probably exposed to endocrine disruptors was associated with 
by gardeners provide inadequate protection even for contact with pesticides over a short period of time (28). Thus, more emphasis should be given on awareness-raising activities and increase of the communication of chemicals hazard/risk.

Health care specialists are expected to use PPE more extensively to protect themselves from infectious diseases and pathogens $(29,30)$. Nevertheless, these PPEs are not adequate for protection from chemicals and lack of compliance is evident regarding PPEs, even among medical technicians (31). Consequently, the observed almost universal use of PPEs by health care specialists in the present study is potentially misleading. Regarding compliance of the medical staff engagement of the personnel in auditing PPE use and reporting activities may significatnly improve compliance (32).

Health care specialists are often asked to treat cases that are linked with exposure to different chemicals. In the present study, $60 \%$ of responders were informed regarding the safe use of chemicals or actions to be undertaken in case of accident. In the latter situation, the National Poisoning Centre is considered the reference point for information for the vast majority of medical doctors. However, the National Poisoning Centers are less often consulted when emergency poisonings are treated in the primary or tertiary care centers (33). Data legally required to be declared to National Poisoning Centers should be harmonized within EU and the new regulatory framework, which is the primary aim of these legal frameworks $(34,35)$.

In conclusion, on a national level, awareness-raising campaigns are imperative $(36,37)$, in collaboration with trade unions and health care professional associations, in order to alert professionals regarding the safe use of chemicals to protect human health and the environment.

\section{References}

1. Shukla KP, Singh NK and Sharma S: Bioremediation: developments, current practices and perspectives. Genet Eng Biotechnol J 3: 1-20, 2010.

2. Winder C, Azzi R and Wagner D: The development of the globally harmonized system (GHS) of classification and labelling of hazardous chemicals. J Hazard Mater 125: 29-44, 2005.

3. Morita T and Morikawa K: Expert review for GHS classification of chemicals on health effects. Ind Health 49: 559-565, 2011.

4. Brekelmans P, de Groot R, Desel H, Mostin M, Feychting K and Meulenbelt J: Harmonisation of product notification to Poisons Centres in EU Member States. Clin Toxicol 51: 65-69, 2013.

5. Petróczi A, Naughton DP, Mazanov J, Holloway A and Bingham J: Performance enhancement with supplements: Incongruence between rationale and practice. J Int Soc Sports Nutr 4: 19, 2007.

6. Cohen J: Statistical power analysis for the behavioral sciences 2nd edition. Lawrence Erlbaum Associates, Hillsdale, NJ, 1988.

7. Sairat T, Homwuttiwong S, Homwutthiwong $\mathrm{K}$ and Ongwandee M: Investigation of gasoline distributions within petrol stations: Spatial and seasonal concentrations, sources, mitigation measures, and occupationally exposed symptoms. Environ Sci Pollut Res Int 22: 13870-13880, 2015.

8. Sirdah MM, Al Laham NA and El Madhoun RA: Possible health effects of liquefied petroleum gas on workers at filling and distribution stations of Gaza governorates. EMHJ 19: 289-294, 2013.

9. Moura-Correa MJ, Jacobina AJ, dos Santos SA, Pinheiro RD, Menezes MA, Tavares AM and Pinto NF: Exposure to benzene in gas stations in Brazil: Occupational health surveillance (VISAT) network. Cien Saude Colet 19: 4637-4648, 2014 (In Portuguese).

10. Fenga C, Gangemi S, Giambò F, Tsitsimpikou C, Golokhvast K, Tsatsakis A and Costa C: Low-dose occupational exposure to benzene and signal transduction pathways involved in the regulation of cellular response to oxidative stress. Life Sci 147: 67-70, 2016.
11. Karimi A, Eslamizad S, Mostafaee M, Momeni Z, Ziafati F and Mohammadi S: Restrictive pattern of pulmonary symptoms among photocopy and printing workers: A retrospective cohort study. J Res Health Sci 16: 81-84, 2016.

12. Pirela SV, Lu X, Miousse I, Sisler JD, Qian Y, Guo N, Koturbash I, Castranova V, Thomas T, Godleski J, et al: Effects of intratracheally instilled laser printer-emitted engineered nanoparticles in a mouse model: A case study of toxicological implications from nanomaterials released during consumer use. NanoImpact 1: 1-8, 2016.

13. Sato Y, Kubo S, Takemura S, Sugawara Y, Tanaka S, Fujikawa M, Arimoto A, Harada K, Sasaki M and Nakanuma Y: Different carcinogenic process in cholangiocarcinoma cases epidemically developing among workers of a printing company in Japan. Int J Clin Exp Pathol 7: 4745-4754, 2014.

14. Schyllert C, Rönmark E, Andersson M, Hedlund U,Lundbäck B, Hedman L and Lindberg A: Occupational exposure to chemicals drives the increased risk of asthma and rhinitis observed for exposure to vapours, gas, dust and fumes: A crosssectional population-based study. Occup Environ Med 73: 663-669, 2016

15. Birks L, Casas M, Garcia AM,Alexander J,Barros H,Bergström A Bonde JP, Burdorf A, Costet N, Danileviciute A, et al: Occupational exposure to endocrine-disrupting chemicals and birth weight and length of gestation: A European meta-analysis. Environ Health Perspect 124: 1785-1793, 2016.

16. Singh $Z$ and Chadha P: Textile industry and occupational cancer. J Occup Med Toxicol 11: 39, 2016.

17. Sathar F, Dalvie MA and Rother HA: Review of the literature on determinants of chemical hazard information recall among workers and consumers. Int J Environ Res Public Health 13: 13 , 2016.

18. Bouchard C: Literacy and hazard communication: Ensuring workers understand the information they receive. J AAOHN 55: 18-25, 2007.

19. Beaufils E, Hommet C, Brault F, Marqué A, Eudo C, Vierron E, De Toffol B, Constans T and Mondon K: The effect of age and educational level on the cognitive processes used to comprehend the meaning of pictograms. Aging Clin Exp Res 26: 61-65, 2014

20. Martí Fernández F, van der Haar R, López López JC, Portell M and Torner Solé A: Comprehension of hazard pictograms of chemical products among cleaning workers. Arch Prev Riesgos Labor 18: 66-71, 2015 (In Spanish).

21. Vaillancourt R, Pouliot A, Streitenberger K, Hyland S and Thabet P: Pictograms for safer medication management by health care workers. Can J Hosp Pharm 69: 286-293, 2016.

22. Ta GC, Mokhtar MB, Mohd Mokhtar HA, Ismail AB and Abu Yazid MF: Analysis of the comprehensibility of chemical hazard communication tools at the industrial workplace. Ind Health 48: 835-844, 2010.

23. Klaschka U: The hazard communication of fragrance allergens must be improved. Integr Environ Assess Manag 9: 358-362, 2013.

24. Andrade-Rivas F and Rother HA: Chemical exposure reduction: Factors impacting on South African herbicide sprayer's personal protective equipment compliance and high risk work practices. Environ Res 142: 34-45, 2015.

25. Ceballos DM, Whittaker SG, Lee EG, Roberts J, Streicher R, Nourian F, Gong W and Broadwater K: Occupational exposures to new dry cleaning solvents: High-flashpoint hydrocarbons and butylal. J Occup Environ Hyg 13: 759-769, 2016.

26. Park H, Park HD and Jang JK: Exposure characteristics of construction painters to organic solvents. Saf Health Work 7: 63-71, 2016.

27. Quinteros E, Ribó A, Mejía R, López A, Belteton W, Comandari A, Orantes CM, Pleites EB, Hernández CE and López DL: Heavy metals and pesticide exposure from agricultural activities and former agrochemical factory in a Salvadoran rural community. Environ Sci Pollut Res Int 24: 1662-1676, 2017.

28. Beránková M, Hojerová J and Peráčková Z: Estimated exposure of hands inside the protective gloves used by non-occupational handlers of agricultural pesticides. J Expo Sci Environ Epidemiol 27: 625-631, 2017.

29. Honda $\mathrm{H}$ and Iwata $\mathrm{K}$ : Personal protective equipment and improving compliance among healthcare workers in high-risk settings. Curr Opin Infect Dis 29: 400-406, 2016.

30. Gralton J, Rawlinson WD and McLaws ML: Health care worker's perceptions predicts uptake of personal protective equipment. Am J Infect Control 41: 2-7, 2013. 
31. Dukic K, Zoric M, Pozaic P, Starcic J, Culjak M, Saracevic A and Miler M: How compliant are technicians with universal safety measures in medical laboratories in Croatia?-A pilot study. Biochem Med 25: 386-392, 2015.

32. Hennessy KA and Dynan J: Improving compliance with personal protective equipment use through the model for improvement and staff champions. Clin J Oncol Nurs 18: 497-500, 2014.

33. SchurterD, Rauber-Lüthy C,Jahns M,Haberkern M,Kupferschmidt H, Exadaktylos A, Eriksson U and Ceschi A: Factors that trigger emergency physicians to contact a poison centre: Findings from a Swiss study. Postgrad Med J 90: 139-143, 2014.

34. Settimi L, Orford R, Davanzo F, Hague C, Desel H, Pelclova D, Dragelyte G, Mathieu-Nolf M, Adams R and Duarte-Davidson R: Development of a new categorization system for pesticides exposure to support harmonized reporting between EU Member States. Environ Int 91: 332-340, 2016.

35. de Groot R, Brekelmans P, Desel H and de Vries I: New legal requirements for submission of product information to poisons centres in EU member states. Clin Toxicol: Jun 23, 2017 (E-pub ahead of print) doi: 10.1080/15563650.2017.1339888.
36. Walsh C: CLP activities and control in Ireland. Ann Ist Super Sanita 47: 165-170, 2011.

37. Pistolese P and Scimonelli L: CLP Regulation and REACH Regulation: Links, implementation and control in Italy. Ann Ist Super Sanita 47: 157-164, 2011. Attribution-NonCommercial-NoDerivatives 4.0 International (CC BY-NC-ND 4.0) License. 